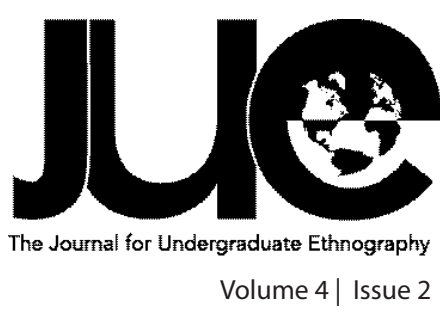

\title{
Interactions with the Outside: Exploring Non-Profit Resource Mobilization for Hispanic Immigrants in the Washington D.C. Metro Area
}

\author{
Alexandra Olsen \\ Florida State University, ago11@my.fsu.edu
}

\section{ABSTRACT}

his research looks at the interaction between a non-profit that serves lowincome immigrants, the community, current immigration policy, and the immigrant population to understand the impact of this system on the growing Hispanic immigrant population in the DC metropolitan area. Over a period of 3 months the external and internal dynamics of the non-profit were observed through participant observation and through qualitative interviews. From this, the effectiveness of the current resource framework is assessed and the underlying processes involved in resource mobilization are analyzed. Drawing elements from the social movements framework, the major resources utilized and the processes of mobilization will be examined within the non-profit context. These resources and strategies propose a model of resource mobilization within the non-profit where cultural and human resources are emphasized to offset fundamental changes in how material resources are utilized, while socio-organizational and human resources are used to offset the impact of unfavorable policy towards immigrants. The implications of this system for the Hispanic immigrant population are discussed along with areas for future research.

Keywords: Immigration, Non-Profits, Resource Mobilization, Policy 


\section{INTRODUCTION: THE IMPORTANCE OF THE HISPANIC IMMIGRANT POPULATION}

As the fastest growing immigrant group, Hispanics have made one of the largest impacts on the U.S. in all areas (economic, social, and cultural) and are only continuing to have a significant presence throughout the country. The 2010 United States Census found that the Hispanic population increased by 15.2 million between 2000 and 2010 (US Census Bureau 2011). Overall, there are 50.5 million Hispanics within the United States according to the 2010 census, with an estimated 11.7 million undocumented immigrants in the United States as of 2012 (2011; Passel et al. 2013).

Given that there are 11 million undocumented Hispanic immigrants, with about two million of them children who were brought here by their parents, it goes without saying that there are many social problems associated with such a large group of people living in fear of deportation and without structural opportunities to improve their lives (Passel et al. 2013; Kullgren 2003, 1630; Hall et al. 2010, 491-501). Because of their lack of legal status, many undocumented workers have been exploited, work in dangerous conditions, or are even held against their will (2010a 492-495; Logan et al. 2009, 3-10). Undocumented women face additional obstacles including domestic violence, forced prostitution, forced labor, and sexual assault (Ingram et al. 2010, 858-865; Hazen \& Soriano 2007, 564; Raymond \& Hughes 2003). Undocumented women who are victims of domestic abuse have the additional fear of being deported or losing their status if they leave their abuser (2010b, 858-860; Rizo \& Macy 2011, 250-251). As many of these women may not speak English, are still unfamiliar with the United States, are oftentimes afraid of the police, and have limited opportunities to escape from their abuser it is difficult for them to get help even if they want assistance (2010b, 858-861; 2011, 251-253). Most importantly, all undocumented immigrants face a constant fear of deportation and uncertainty about their future because of their legal status. As there is no path to citizenship for these 11 million people at the current time, they live with worries of their families being separated, losing years of hard work, and having to return to their home country. Though undocumented immigrants face a large range of struggles, immigrants as a whole face a unique set of struggles when coming to the United States. Most immigrants are employed in low-skill high-labor sectors such as the agricultural and service industry (Parrado \& Kandel 2011, 626-624; Flippen 2012, 32). These are also industries that on average pay minimum wage or less, meaning that many immigrants live in or near poverty. Language barriers are also a significant issue for Hispanic immigrants, as not knowing English makes life more difficult and can lead to further discrimination (Finnie \& Meng 2005, 1935).

Because of the connection between the social problems, struggles that immigrants (and within this context Hispanic immigrants) face, and a lack of resources, it becomes important to examine how resources are mobilized to combat these issues. As immigration policy holds a significant role in their struggles, the extent to which this limits resource availability is also important to consider. Thus, this research will seek to examine the resource mobilization of a non-profit that serves primarily the Hispanic immigrant community to better understand the implications of organizational processes for the capacity and continuity of resources provided to their clients.

\section{UNDERSTANDING NON-PROFIT DYNAMICS FROM A SOCIAL MOVEMENTS PERSPECTIVE}

Previous research has shown that the benefits of non-profits that serve immigrants are numerous. These non-profits act as community centers, are essential to supplement the lack of governmental resources, encourage the economic viability of immigrants, act as advocates for racial and ethnic minorities, serve as liaisons between governmental organizations and other nonprofit organizations, and are a direct link into immigrant communities (De Leon et al. 2009, 3-10; Huxham \& Vangen 1996, 5-8; McCarthy \& Walker 2010, 215-230). The goal of non-profits, in general, is to "alter prevailing patterns of resource stratification and redirect resources" (Edwards \& McCarthy 2007, 116119). Given the many struggles that the growing population of Hispanic immigrants faces in the United States, it is important to understand how these problems are being addressed. As resource mobilization to combat social problems is at the heart of many Hispanic immigrant-serving non-profits, it is important to understand how these processes work. Additionally, it is clear in the literature that strategic decisions made by non-profits directly affect how successful an organization can be. As the success of an organization translates to the continuity and capacity of the organization, it is important to understand the implications of the strategic decisions made by non-profits as well. 
Resource mobilization provides a useful framework for understanding non-profits, as they both share the trait of "undertaking actions to further the social change goals". Thus resource mobilization framework can be used as a starting point to understand the mobilization in non-profits (Edwards \& Gillham 2013; McCarthy \& Walker 2010, 220). Social movement literature focuses on two facets of resource mobilization that are particularly important to this investigation: the type of resources needed and utilized, and the processes behind mobilizing these resources. Edwards and McCarthy (2007a, 116-120), drawing upon the many conceptualizations of resource types, provide evidence that resources that social movements utilize are moral, cultural, human, material, and social-organizational resources.

Cultural and moral resources include legitimacy, solidarity support, sympathetic support, and celebrity (Edwards \& McCarthy 2007, 116-125; Edwards \& Gillham 2013). An example of this would be a celebrity endorsing an organization or cause. Moral resources, specifically legitimacy, have been found to be significant to community based organizations that seek to reach audiences that lack resources (Walker \& McCarthy 2010, 223). Socio-organizational resources are distinctly separate from cultural and moral resources, as this group includes infrastructures, social networks, and organizations (2007, 116-125; 2013). This type of resource is composed of friends of movement participants who could potentially be recruited for the cause, partner organizations where cooperation could occur, or other structures within the community that can be accessed by the social movement for their advantage. Human resources, as defined by Edwards \& McCarthy, are not only the humans involved with the movement, but also the skill sets that they bring to the movement (2007, 116-125). Human resources are significant for social movements and organizations because they are the actors that mobilize the ideas and goals of the movement. Similarly, this could be seen happening within non-profit organizations with the staff providing direct change through legal and social services. Finally there are material resources, which include funds, meeting space, and supplies (2007. 116-130; 2013). These are the most tangible and basic resources that social movements utilize.

All of these resources in some manner can be applied to the case of the non-profit. Though the non-profit is not actively trying to make an ideological change in many cases, the moral and cultural support of communities can help sustain an organi- zation. This can be through increased volunteers or donations. (Zald \& Umseen 1987, 263; Zald \& McCarthy 1987, 172-174) Equally as important, the non-profit desires material and human resources. Once these resources are obtained, it is then the function of the social movement or social movement organization to begin mobilizing these components. This can be done through creating organizations and building organizational capacity, mobilizing money, mobilizing actors, and creating resources and mobilization potential through collective action $(2007,116$ 120). How effective these organizational processes are directly affect the continuity and capacity of organizations (Downey \& Rohlinger 2008, 32; 1987, 161 \& 172-174; Walker \& McCarthy 2010, 218).

As important as it is to understand resource mobilization, it is equally important to understand how organizations make strategic choices with their resources. These choices affect the continuity and capacity of the organization, and consequently affect how effective the non-profit can be with their resources. Regardless of the lack of research on the mobilization processes themselves, there has been substantial research done on how strategic choice is made in non-profit organizations. How effective non-profits are at achieving these goals depend on a multitude of factors including the amount of funding available, the effectiveness of the board, the existence of a system to measure organizational outcomes, legitimacy in the community, and the success at outreach (De Leon et al. 2009, 12-14; Huxham \& Vangen 1996, 6-10; Walker \& McCarthy 2010, 232). One area that the research on non-profits has not considered is how relationships with outside organizations can affect the ability for a nonprofit to fulfill its mission. Drawing from the social movements literature once again, it has been found that social movement organizations often compete with one another, instead of cooperating, even at times when they have similar missions (Downey \& Rohlinger 2008, 28; Zald \& McCarthy 1987, 173). Whether this is true within the non-profit sector, especially with the non-profit's unique goal of directly maximizing social change outcomes, is something that is important to examine to better understand what this means for the success of their organization.

Finally, it is important to note the limiting factor of public policy, when looking at the extent to which non-profits can help alleviate social problems that Hispanic immigrants face because of the significant problem of legal status within this community. 
Given the fact that there are around 11 million undocumented Hispanic immigrants in the US, with no policy to address the situation, the non-profit can only provide so much. Under current immigration law there are few legal fixes for an immigrant here without authorization. If an undocumented immigrant was brought to the US under the age of 16, there is Deferred Action for Childhood Arrivals which provides temporary relief from fear of deportation and a work permit, but this is not a path to citizenship. Additionally, undocumented immigrant victims of qualifying crimes, such as domestic violence, human trafficking, or sexual assault, are qualified for special U-visas and T-visas that can lead to citizenship. Past these two main options that only a limited portion of the population qualify for, there are no means to change legal status. In rare cases other forms of legal relief can be employed, but these are few and far in-between. Given the large body of literature showing the negative affect of legal status on education attainment and success, salary, and quality of work conditions, it is clear that only so much can be done without a federal public policy change (Passel et al. 2013; Kullgren 2003, 1633; Hall et al. 2010, 495-510; Logan et al. 2009, 8-13). Thus, non-profits that target the Hispanic immigrant population face the unique challenge of trying to find an appropriate legal remedy for qualifying clients, while trying to address the symptoms of lack of legal status for undocumented clients who do not qualify for current legal remedies. How non-profits deal with this challenge has not been examined in past research, but is integral when trying to understand the extent to which nonprofits can mobilize their resources.

Given the significance of the issues arising with the influx of Hispanic immigrants into the United States coupled with the crucial role that non-profits play in assisting this population, it is important to better understand the way that the non-profit functions specifically in regards to resources. Hence, this investigation attempts to answer the following questions: How do nonprofits mobilize their resources to meet the needs of the Hispanic immigrant population and how effective are these strategies? How do non-profits and their resources interact with policy to affect the effectiveness at meeting the needs of the Hispanic immigrant population?

\section{METHODOLOGY}

\section{Washington D.C.}

Within Washington D.C., 9.1\% of the population identifies as Hispanic and $13.8 \%$ of the population identifies as Hispanic in the metropolitan area (Pew Hispanic Center 2011; George Mason University Center for Regional Analysis 2011). This population is only growing, with a significant increase in the Hispanic population of Washington D.C. within the past 10 years. In general, compared to other large cities, Washington D.C. is one of the only cities that still has a rapidly growing Hispanic immigrant population, with only more growth in Dallas and Atlanta. (George Mason University Center for Regional Analysis 2011). Even more importantly, there has been even greater growth in the metro area of Washington D.C. The D.C. metro area includes the District of Columbia, counties in Maryland (Calvert, Charles, Frederick, Montgomery, and Prince George's), and counties in Virginia (Arlington, Clarke, Culpeper, Fairfax, Fauquier, Loudoun, Prince William, Rappahannock, Spotsylvania, Stafford, and Waren).

Given that the area is well connected through transportation and community organizations, the impact of this growth has affected the D.C. area as a whole by increasing the need for resources for Hispanic immigrants. To meet these needs, many non-profits in the area share the goal of helping immigrants with legal matters and assisting in their transition into the United States. In the metro there are over 500 non-profits serving immigrants, with 132 catering to the needs of the Hispanic immigrant population (De Leon et al. 2009, 2). As there is a large population spread throughout the whole area, the non-profit infrastructure that serves this community has recently had a great increase in demand. As it was noted earlier, the percentage of Hispanic immigrants living under or at poverty level is very high; thus, lowincome legal and social services are integral support systems that can augment their success within the US. This is even more significant for those here without documentation or in vulnerable situations, such as those in abusive relationships or those who have been trafficked.

Jurisdiction challenges of a metro area are unique here. As these non-profits serve three different districts there are many challenges presented. Because attitudes within each jurisdiction vary in terms of attitudes towards immigrants, this can affect 
funding and the amount that non-profits are able to help (De Leon et al. 2009, 3-5). The area has been a place of both support and rejection of the Hispanic immigrant community. This is personified in local governmental policies in two jurisdictions, within the municipality of Washington D.C. and in Prince William County, Virginia.

Within Prince William County there was a stark backlash to a large influx of immigrants. Specifically, a community member named Greg Letiecq formed an organization called Help Save Manassas to drive undocumented immigrants out of Manassas and the Prince William communities (Guterbock et al. 2010). To do this, his organization pressured the Board of Supervisors of the town to pass General Order 45 on July 10, 2007 (Prince William County Government 2013). This order stated that "The Police Department will investigate the citizenship or immigration status of any person who is lawfully detained for a violation of a state law or County ordinance, if there is probable cause to believe such person is in violation of federal immigration law and when such inquiry will not expand the duration of the detention. Racial profiling is expressly prohibited, as emphasized in existing General Order 2.01, Section C, 56,'(Deane 2007). Though technically racial profiling was prohibited, the immigrant community within the county grew increasingly concerned about the possibility of profiling. Despite their concerns and protests, the order was passed. This led to increased racial tension within the county and conflict between the police force that increasingly did not want to enforce the order, and a Board of Supervisors that was standing behind the measure due to pressure from the community (2010). Police were increasingly concerned that these policies would decrease trust in the community, making it harder to fight real crime when it occurred. This policy also drove Hispanic immigrants out, both those with documentation and without, devastating the housing market in the area. Eventually the measure was repealed on April 29,2008, when a directive was passed requiring police officers to ask about the immigration status of all who are arrested, gives the officers discretion of whether to ask before arrest, and affirms the police department's commitment to protect victims of crimes regardless of legal status (2013). Even so, a report done by the Prince William County police department found that the implementation of General Order 45 eroded confidence in the community and in police officers in the eyes of the Hispanic immigrant population (2010).
In stark contrast to the policy enacted in Prince William County, within D.C. a measure was passed that works to protect Hispanics against racial profiling in the wake of State Bill 1070 passed by Arizona. State Bill 1070 has been one of the most stringent immigration measures passed within the last few years. Before being overturned by the Supreme Court, it required anyone over the age of 14 who was not a citizen to carry registration documents with them at all times, and if stopped without them they could receive a misdemeanor. The ability for state police to investigate immigration status, was upheld, given the condition that racial profiling does not occur. Even so, the potential for racial profiling is still very high. A similar law was passed in Alabama; House Bill 56 limited undocumented immigrants from every aspect of life, from being able to open a utilities account to registering an animal (Hispanic Interest Coalition of Alabama, et al vs Robert Bentley, 2011). Since passing though, the appeals court of Alabama has limited many of the more stringent provisions within the bill (2011). Critics of these policies cite the tendency for racial profiling to occur under this law and see the law as a civil rights violation. In response to both of these bills, Washington D.C. passed a policy that has been called "anti-Arizona" to protect immigrants living within their borders. The executive order, signed by Mayor Vincent C Grey in October 2011 "clarifying that the District's public-safety officials will not inquire into the immigration status of individuals or transmit information about immigration status to federal agencies except when that status pertains directly to a criminal investigation," (Executive Office of the Mayor, 2011). This policy works to both keep immigrants from fearing being detained while also rewarding undocumented immigrants who are engaging in legal behavior and contributing to life in the United States. Along with President Obama's immigration reform, the threat of legal repercussions for immigrants within the District of Columbia is a much smaller fear than in other areas.

Consequently, the Washington D.C. metro area presents an interesting case study to look at how urban areas with burgeoning immigrant populations develop and improve resource mobilization frameworks. Given the large demand for services, coupled with a growing immigrant population in a metro area formerly unaccustomed to this group, there needed to be a better understanding of how the area was dealing with this influx. Coupled with the extra challenges of multiple jurisdictions, the 
distribution of resources in the area is complex and adds to the question of how non-profits meet community needs.

\section{Data Collection Methods and the Field Setting: The Helping House}

The setting chosen to conduct research was a non-profit, given the pseudonym The Helping House for confidentiality purposes. All those mentioned throughout the study have also been given pseudonyms for their privacy. As government assistance for immigrants is limited, the non-profit is the main body that aims to fill the gap of resources. I chose this location for three main reasons. First, it is an organization that mainly serves the Hispanic population of the entire Washington D.C. metro area. Second, it is an organization that offers more comprehensive services, specifically legal services, as this is one of the most pressing concerns for many Hispanic immigrants. Third, it is one of the oldest in the area and most reputable.

The Helping House is a well-established organization that mainly serves Hispanic immigrants, but has helped immigrants from throughout the world. Their services are available to all immigrants within the Washington D.C. metro area, but some are restricted due to funding guidelines. They provide social and legal services for low-income immigrants as well as providing special services for immigrants who are dealing with issues of domestic abuse or human trafficking. The legal services department of the organization is considerably larger than the social services side, a department that mainly exists to meet the needs of immigrants dealing with domestic abuse or human trafficking. This department consists of lawyers, paralegals, and Board of Immigration Accredited (BIA) Representatives. A BIA representative is able to submit immigration applications and represent clients in deportation court, but does not have to hold a law degree. Cases that the legal team would take ranged from petitioning for refugee status, applying for Deferred Action for Childhood Arrivals (DACA), applying for special visas on the basis of crimes, and a family law unit to assist domestic violence survivors. Social services include a therapist and social workers. The purpose of this department is to help domestic violence and human trafficking survivors deal with the trauma they have experienced so that they can lead successful lives but also testify against their abusers without being re-traumatized. They can also help survivors of abuse with safety planning, finding safe shelter, obtaining a job, and meeting the basic needs of them- selves and their children. The social services department aims to assist those who have been trafficked to adjust to life in the US, teaching them how to get jobs, find housing, and navigate applying for special benefits for trafficking victims. Consequently, this non-profit tackles some of the most pressing needs of the Hispanic immigrant population.

Another distinct feature of the non-profit is the legitimacy it holds in the community. All staff members are required to speak at least English and Spanish fluently and special attention is paid to cultural sensitivity. Hispanics who understood the needs of the immigrant community originally founded the organization, a value the organization continues to promote internally and externally. This is reflected in the demand for the non-profit's services, where often the receptionist would have to turn away people because appointments were booked solid for the upcoming month as soon as they were made available.

At the time of research, the Helping House had 29 permanent staff members. Everyone at the non-profit was very enthusiastic about his or her jobs. Even during lunch breaks conversation would often drift to an immigration related topic. All members of the staff worked long hours, usually between 50 and 60 per week, sometimes even coming in on the weekend. Every staff member was proficient in English and Spanish with the exception of a few people in the administration. All the staff is under the age of 40, with the exception of the accountant and one senior staff attorney. All lawyers had past experience working in immigration law or with immigrants/international populations. The majority of the staff is also married and childless, with only four staff members having children. All employees hold at least a Masters or professional degree. Most significantly, all have a personal connection to immigration or commitment to public service related to empowering marginalized communities.

Over a period of three months from May 2013 until August 2013, I came in for three days a week, eight hours per day. My typical duties included organizing grant databases, researching the history of the organization through searching for historical documents and interviewing first-hand sources, writing articles about immigration policy, sitting in on legal trainings, assisting with program development, researching donors and creating board member profiles, and listening to immigrants' stories. Each day I would write notes throughout the day into a word document on the computer. I paid attention to the daily routine 
of the office, listening to casual conversations and engaging in more formal matters. I was allowed to attend all of the trainings for the legal interns (all of whom are in law school), social services trainings, and sit in on some administrative meetings. The intern area was in the center of the office, in an open area where all that was going on could be observed. In this area, there were constant interactions between the staff and interns, as well as some interactions with clients.

After building a rapport with The Helping House over this period I conducted six qualitative interviews with the staff. These staff members were picked to ensure proportional representation of all departments, genders, and races. The length of time that the interviewees had worked at the organization ranged from 3 weeks to 10 years. The questions asked in these interviews were meant to gain a better understanding of the organization, its strengths and weaknesses, and the personal insights that the staff could provide about their work. The questions were open-ended, leaving much room for in-depth discussion about topics that could arise within the interview. I asked questions about their positions, involvement, opinions on the organization's functioning, and engagement in the broader community. The interview closed with asking a reflective question about the impact that the interviewee felt they had made on the population and asking for any other thoughts. The purpose of this was to wrap up the interview naturally and get a sense for the motivations of the people dedicating their career to public service. Finally, basic demographic questions were asked about age, race, education level, religious affiliation, employment, marital status, and number of children.

Though each interview addressed all of these key questions, due to the open-ended nature of many of the questions, each interview trailed off to focus on a particular interesting idea or process mentioned by the interviewee. This was directly related to the specialized role each employee interviewed played in the organization. For example, interviews with the different lawyers focused on various facets of legal issues faced by the Hispanic immigrant population while the interviews with administration and social services shed more light on the relationship on the non-profit to the community as a whole. Going even further, each individual had detailed insights about their function in the resource mobilization chain created by the non-profit.

\section{Data Analysis Framework}

Evaluation of the data was originally done through open coding. All participant observation notes and interviews were reviewed to look for common themes and patterns. As the notes were reviewed, short memos were written highlighting key points of discussion at the organization, information about how the non-profit ran, and any other significant information about how the organization strived to meet its mission statement. The memos were then read over and the discussion of resource mobilization was identified. A salient theme throughout the data was a discussion of how and through what means the non-profit could maximize their impact on the Hispanic immigrant community. From here, further research was done looking at theories of resource mobilization, culminating in the framework presented by social movement scholars. Thus, the data and coding were then evaluated according to the definitions of this mobilization theory to understand the types of resources the non-profit utilizes, how the organization makes strategic decisions, and how they mobilize these resources to ensure capacity and continuity.

Under this framework, the data was recoded to identify the human, material, cultural, and socio-organizational resources of the organization based on the definitions proposed by social movement organization. Whenever someone mentioned a resource in an interview, this was coded according to what type of resource it was. Additionally participant observation notes were coded to identify resources through reflections on the environment of the non-profit, disposition of the staff, everyday occurrences at the organization, and history of the organization. The following table presents examples of each resource and an example from the data: 


\begin{tabular}{|c|c|}
\hline Resource & Example from Data \\
\hline $\begin{array}{l}\text { Human Resources (staff, volunteer, interns, specialized } \\
\text { immigration knowledge, duties) }\end{array}$ & $\begin{array}{l}\text { "I supervise other attorneys, paralegals, BIA accredited reps, } \\
\text { and interns in their work doing direct services." (Juanita's, a } \\
\text { lawyer, description of her responsibilities) }\end{array}$ \\
\hline Material Resources (Money, Office Space, Supplie, Social) & $\begin{array}{l}\text { "One of the things I like about the Helping House is how } \\
\text { accessible it is via public transport" (Deborah, an administrator, } \\
\text { discussing strengths of the organization) }\end{array}$ \\
\hline $\begin{array}{l}\text { Cultural and Moral Resources (Legitimacy in the community, } \\
\text { cultural sensitivity, ther non-profits in the area) }\end{array}$ & $\begin{array}{l}\text { "When I asked about referrals today, Deborah told me that the } \\
\text { Helping House is well known and trusted in the community. } \\
\text { She estimated that over } 50 \% \text { of these clients come to Ayuda } \\
\text { through these means. Otherwise, clients come through referrals } \\
\text { from other organizations. These vary depending upon the type } \\
\text { of case." (from participant observation notes) }\end{array}$ \\
\hline $\begin{array}{l}\text { Socio-Organizational Resources (personal relationships, social } \\
\text { networks) }\end{array}$ & $\begin{array}{l}\text { "[So would you say that it's more about the personal } \\
\text { relationships?] I feel like it is, yeah! Because then people } \\
\text { contact you directly, and it's like you know a fellow non-profit } \\
\text { you know worker" (Joe, a lawyer, discussing referrals between } \\
\text { non-profits) }\end{array}$ \\
\hline
\end{tabular}

Then, the notes were coded as to how the Helping House mobilizes money and actors, and makes strategic decisions. Mobilization of money and actors include explanations as to how the organization utilizes the four types of resources. Here is where intersectionality between resources begins to become important because these organizational processes often involve the use of multiple resources. The following table provides examples of the non-profit's organizational processes as they were coded. 


\begin{tabular}{|c|c|}
\hline Organizational Processes & Example from Data \\
\hline Mobilization of Money & $\begin{array}{l}\text { "It is crucial to the Helping House's future success that } \\
\text { we diversify our funding sources. We need to do this } \\
\text { through building community support so that people give } \\
\text { meaningful donations, repeatedly" (Jane, an administrator, } \\
\text { explaining changes in funding structures) }\end{array}$ \\
\hline Mobilizing Actors & $\begin{array}{l}\text { "I think that's one of our strengths too, where we're able } \\
\text { to like draw upon the pool of interns that we've trained. I } \\
\text { guess I've never really thought about it that much but our } \\
\text { internship program if we can, if an intern applies and we } \\
\text { really liked them, I mean it's pretty likely that they'll be } \\
\text { hired." (Joe, a lawyer, discussing trends in employment) }\end{array}$ \\
\hline Strategic Decision-making & $\begin{array}{l}\text { "Deciding what areas of your mission are going to grow as } \\
\text { your funding grows through dialogue with the staff and } \\
\text { board is crucial" (Deborah, an administrator, discussing } \\
\text { how choices made about the allocation of resources) }\end{array}$ \\
\hline
\end{tabular}

Finally, the notes were coded for what these organizational processes mean for the continuity and capacity of the organization. Examples of this were found when looking at the intersection between specific resources and strategic decision-making. An example of this is when Deborah details the objective of a new funding model to supplement changes in support, "You have to be different, if you do the same thing and call out of the blue for money, that's not effective. I'm in the business of developing relationships. There's a difference between when an organization calls you and you're excited to support it and really believe in it, it's different when you hear the non-stop NPR fundraising or calls you out of the blue". This example directly shows how the organization has made a strategic decision to change something about their organization based on a changing balance of resources that can be accessed. Thus, these relationships were coded in the notes through identifying intersections between resources, and dialogue on how to leverage these intersecting resources against each other, for the purposes of continuity and capacity of the organization.

\section{Limitations}

It is critical to mention limitations to this investigation. For one, this case study is specific to the Washington D.C. metro area. This means that though the framework developed could be tested in similar metro areas, it is not an absolute model to how organizations mobilize their resources. Additionally, this investigation only was able to examine one non-profit and their interactions with other community entities. To get a complete picture of the relationships between non-profits, it would have been necessary to observe non-profits other than the one stud- 
ied. Though the length of time spent at the organization was substantial (3 months), a longer period of observation could lead to more discoveries about functioning and also provide more data on how the organization evolves over time.

\section{DATA AND ANALYSIS}

This case study of a non-profit that serves primarily Hispanic immigrants presents an opportunity to get a nuanced view of resource mobilization within the non-profit. Drawing elements from the social movements framework, the processes of mobilization will be examined within the non-profit context. From this it is clear that resources interact and support one another, and that these interactions have significant implications on how resources are mobilized. This is discussed within the analysis of organizational processes, leading to the conclusion that organizations make strategic decisions based on how they believe they can leverage their existing resources. These resources and strategies propose a model of resource mobilization within the non-profit where cultural and human resources are emphasized to offset fundamental changes in how material resources are utilized. In addition, socio-organizational and human resources are also used to try and offset the impact of unfavorable policy towards immigrants. Finally, the effectiveness of resource mobilization will be assessed based on field observations to suggest ways in which the non-profit could improve its resource mobilization.

\section{ORGANIZATIONAL PROCESSES}

It is important to understand the implications of resources and the interactions among them on organizational capacity and continuity. This in turn, affects the resources available to the immigrant community. What came out of these interviews and observations, as a whole, was a complex discussion about what resources are available and the debate over how a non-profit should mobilize them. Though this was not originally expected, as a result of the questions aimed at getting a descriptive look at the organization, this significant conflict is highlighted and can be analyzed under an existing resource mobilization framework to advance theory on these processes.

Mobilizing Money: A New Approach

At the time studied, the organization was at a crucial point of trying to build a sustainable funding base. Within the last ten years there have been major shifts in the way that non-profits procure funding. Before the economic recession in 2007 the quantity and amount of funding available through large governmental grants was starting to decrease, with the grants available decreasing significantly after the onset of the recession. Since then, there has been a shift to non-profits depending more on private donations. Thus, the non-profit is at a critical point of working to make themselves sustainable through developing a new funding strategy based on developing personal relationships in the community for the purposes of soliciting for meaningful donations. This is highlighted through Jane's, an administrator, explanation of how her focus as an administrator has shifted because of the shift in funding acquisition.

"The recession changed everything, even though there had been recessions in the past. They're fundamentally trying to change how government support is given out to non-profits in the community. So you're having a really high level dialogue philosophically on what is the function of non-profits and NGOs and how do they get the money when there isn't any money to give, so how are those tough choices made... it's no longer responsible to our clients to rely on large government grants that could be gone tomorrow"

This is not to say that grants were still not a decent part of the budget of the organization, but rather that this is slowly starting to shift. The organization studied did have multiple memorandums of understanding with the federal government and some federal government funding, but these was primarily for their human trafficking programs. State and local government grants were much more prevalent among funding sources but come with restrictions.

Coming along with the use of grants are the challenges of limiting services based on residency; this is even more so a problem at an organization that serves a well-connected, metropolitan community. These limitations significantly limit how effective the non-profit can be at resource mobilization. Though as their funding diversifies this may no longer become a problem, it is definitely an obstacle to being able to serve the largest amount of people. Compounded with the large increase of immigrants to the DC metro area within the past ten years and immigration reform in the works, this could easily become an even larger obstacle in the near future if steps are not taken to significantly 
diversify funding.

As a shift of funding is underway, the non-profit has had to make some considerable changes to funding strategy. Though not visible, this process has not been without tension. In one interview it was noted that the change in funding is as much a cultural change of the organization as it is a funding change. Because of the way the organization was previously funded through grants, there is a lack of comfort with asking community members for support by some staff members at the organization. This is where tension arises between the administrative side of the organization and the direct services side. Because the roles and focuses of the administrative and direct services staff are so different, at times there is a lack of understanding be it because of communication or inherent ideological differences. To try and ease this, there has been a pointed focus on engaging in discussions and explain exactly what the shift in funding means. A large part of this comes from making the distinction between hounding people for money and building a genuinely supportive community donor base. The administration also tries to communicate that the purpose of going past government or large grants is to expand the work that the non-profit does, and explaining that this is the best means through which the organization can expand. As this new funding strategy has had some success in the past year that it has been implemented, the additional question arises of how to allocate these new funds. This breeds an entirely new discussion and point of tension. Though the mission encompasses both legal and social services, which department gets extra resources? The legal services department, though bigger, has a very high demand; does this mean that new funding should go to them? Or should it go to the newer social services department that is trying to grow, as to making the nonprofit's services more comprehensive? A more detailed explanation of these intricate decision making processes by Jane helps clarify what is done to balance all interests.

"It is a constant dialogue, at the end of the day your board and your executive director are making decisions, but I am a very collaborative worker so it's important to me that this just doesn't come down from on high because I think the staff will be unhappy and this trickles down. To explain the overall culture of fundraising is how it all starts. It's about telling our clients that we'll be here tomorrow, if a government grant is cut tomorrow then we'd have to cut all of our funding. From my perspective and those who want to diversify funding, it's more responsible for our clients that we develop a sustainable model of income... at the heart of all of our decisions is the accountability of our clients. As there are so few administrative staff and so many program staff, given that everyone here is very passionate what about the work and committed to the mission, it makes sense that they are protective of their clients and their work. But it's about explaining to them that we're trying to get people to make meaningful gifts instead of looking to meet financial goals, and that may entail some cultural changes in the organization."

There are no easy answers to these questions, but is instead a constant dialogue of where best money could be spent while also trying to figure out how money can best be used to further the mission. What is important, as another staff member noted, that the importance is always placed on furthering the mission and meeting the clients needs. At the heart of every discussion had, that must be what is foremost taken into account.

The question then arises as to how the client's needs are actually measured. This is one significant way that this non-profit is limited. There is no formal evaluation system in place to assess the client's experience, what their needs were and are, and how well their needs were met. Though their successes are apparent in other ways such as the demand for their services, the increase of immigrants to the DC area, the number of successful cases, and positive reputation in the community, a formalized way of evaluating outcomes of their clients could prove to be a useful tool. These statistical and descriptive measures could give a greater voice to the needs of the immigrants in the communities so that a more informed decision could be made about where to allocate new funds.

Mobilizing Future Actors

Training future actors is another important function of the staff for the viability of the organization. The internship programs provided, specifically for law students, help to ensure the future success of the organization in an unintentional way. As Jennifer noted in an interview, law school is about learning how to think rather than how to engage in the daily practice of law.

"With immigration law, it's even more necessary to provide that kind of basic training and you know the further men- 
torship and supervision. Why? Because immigration law is, well, the only other kind of thing that you can compare it to is the tax code, and people joke about the tax code it's insane and like incomprehensible and it's like 1000 pages long."

Because of the complexity of immigration law and lack of applicable knowledge of the interns, each intern has to go through around two weeks of rigorous, daily training to learn how the organization works and about what they will be doing. From there, they receive a lawyer as a mentor and continue to learn as they slowly take on larger caseloads and work more independently. Through teaching the practical skills of meeting with clients, preparing applications, and managing cases the law students get work experience, but the non-profit equally has a pool of potential employees. This is a pool that has been used in the past with five employees being former interns at one point. This allows the organization to maximize the utility of the training resources of the other employees, as hiring from this pool prevents the need for another person to be taught.

The non-profit deliberately attempts to mobilize actors through their efforts to develop human capital through their interns and volunteers. This is indirectly accomplished through the propagation of the importance of immigration issues throughout the community. The time that staff members put into developing interns and volunteers is very significant. This shows an organizational culture of mobilizing others and investing in their staff. This has been a rather successful strategy for them in terms of staff retention given the number of employees who have worked for the non-profit for many years after first being an intern. This has also led to a tighter knit organization, which helps with retention of employees. All of the staff spoke highly of one another and were confident in the employees in their departments and in the entire office. This played an important role in keeping the focus of the office on working productively together, staying focused on the tasks at hand, and communicate effectively.

\section{Mobilizing Other Non-Profits and Community Based Organizations}

Significant to the organization's success is how it is able to mobilize relationships with other non-profits and communitybased organizations. Before discussing their effectiveness in these relationships it is important to mention that the non-profit can only do so much to mobilize these actors. As is noted in the social movements literature, organizations make strategic choices about when to work with other organizations and the terms of those agreements (Downey \& Rohlinger 2008, 4; Zald \& McCarthy 1987). This also holds true within the non-profit community. A good example of this is presented in an anecdote of a conflict when trying to get a client who had a highly valid (meaning that there was a good chance her abuser would try and find her to kill her) domestic abuse case into a shelter. The client's time at a former shelter was almost up, and they were attempting to get her in to another shelter. When trying to get into the other shelter, they faced an issue because the client did not speak English and the shelter did not want to provide translation services. The following is Claudette's (a social worker) description of how the two parties came to agreement.

"The executive director got involved and their executive director was involved, program directors were also involved and eventually we kind of came to an agreement that I would continue to provide case management as they were providing case management and that we would split the cost of translation. Which in terms of the social work field, that's not really a great agreement because you've got two people providing the same service and really it should only be one person so there's no confusion and no conflict between the two. And as such we basically ended up paying for half of the translation that this agency should have been providing. So fortunately the client got into the shelter but it wasn't really a just agreement."

This highlights some of the struggles associated with trying to work with other organizations and difficult choices that the non-profit has to make in these interactions. In this situation, the organization was faced with the dilemma of accepting an unfavorable agreement or not being able to assist their client. Recognizing the importance of providing holistic services and the client's safety, they chose in this situation to accept the agreement regardless of lack of fairness.

Building Organizational Capacity and Continuity through Moral and Cultural and Human Resources

The non-profit aims to build organizational capacity and continuity through the way that they mobilize their actors, money, and make strategic decisions. Specifically, there has been 
a strategic decision made to make the organization more sustainable. This is a cultural shift within the non-profit as well as very clear shift in how resources are utilized. This can be seen through their practices of diversifying their funding, investing in training of interns and volunteers, the building of their board of directors, and developing personal relationships within other organizations to make referrals more effective. To build organization capacity and continuity cultural and human resources have become more significant to offset fundamental changes in how material resources are utilized. In addition, socio-organizational and human resources are also used to try and offset the impact of unfavorable policy towards immigrants.

The changing funding situation of non-profits has increased the need for cultural and human resources to gain funding, so that immigrants in all jurisdictions can take advantage of all the resources the Helping House offers. To offset the lack of material resources available, the organization has made a strategic shift to using cultural and human resources to make up for a lack of large governmental grants; this is essential to sustain funding of the organization. This is done through an increased emphasis for the entire staff to be behind the new method of funding and encouraging their participation in public events that the Helping House participates in to gain monetary support.

"When it comes to a culture of fundraising, it's about a holistic community relationship and if people aren't supportive starting with your own family, starting inside the office, it leads to unhealthy donor relations and missed opportunities. So everyone has to understand that really at all times and in all ways, they are helping to grow the Helping House's community and then raise support for us, but it's a very long-term process."-Jane, an administrator

Their support is crucial for two reasons. For one, the legal and social services departments directly work with the clients, so their insights are appreciated. It is also essential that the entire organization be behind the new system of funding. As Jane, part of the administrative staff, mentions community support starts with the families and the people who work at the Helping House. Without their backing, use of cultural resources to gain support, and without their support on an ideological level, the new method of funding cannot be successful. Thus, increasing the material resource of money, is contingent on the successful interaction between human and cultural resources.
Equally as important to the new funding strategy is the support of the board members of the organization. They are required to attend board meetings and be involved in the decisionmaking processes of the organizations, fundamental to the longterm success of the Helping House. Though the non-profit is stable, it is important for the board to take their responsibilities seriously and be engaged with the organization. Ashley, a part of the administration noted

"Fundamentally they are the governors of the organization...they are the ones that are legally and financially liable for the organization. If it's a stable organization, people will sign onto a board without hesitation, so there's not that danger. But you still need your board to take the responsibility seriously, as they are the leaders and owners of the non-profits."

Previous research has shown the importance of boards for nonprofit success; this plays a less critical role in the short-term success of the non-profit in this case study, as the organization is stable. Instead, an effective board in general is needed for the long-term success of the shift of funding. Currently, the nonprofit has a very new board that does not have extensive experience of being on the boards of non-profits. What comes along with this are miscommunications about what is expected from each party. To combat this, the non-profit has tried to better educate the board about their responsibilities and communicate their expectations before recruiting new board members. Consequently, until the board is more established it will be difficult for their role to be as significant as it would be in an organization with a strong and established board. As of right now that translates into fewer cultural and human resources that can be used to attract funding and support of the organization, with the goal of increasing this in the long term.

Dually, the current weaknesses of the board have been offset through emphasis placed on collective internal decisionmaking. As there has been such a big shift in funding that affects the culture of the organization, special care has been taken to clearly communicate what changes are occurring.

"I think the new funding model was introduced just as, 'well we're doing this now!' as opposed to 'here are the strengths of our organizations, here are the weaknesses of our organization, and that at the heart of all of these decisions is accountability to our clients. So to me, there's nothing more 
important than being accountable to our clients. What I've tried to do is to frame changes in administration as being beneficial to them and their clients, especially because this is an organization with so few administration and so many program staff"- Juan, a lawyer

Because in the past, there have been misconceptions about what exactly the new method of funding looks like, the administration has put in place weekly meetings to discuss the major changes occurring so that everyone has a deep understanding of what is going on. This functions to help with continuity in the long-term, through making the staff feel like they have a say and that their work and opinions are valued. It dually helps build support for the new program so that it can be successful.

The investment that the administration is making in developing the rest of the staff and the board is instead occurring because of a shifting organizational culture as opposed to a need to avert a pressing organizational crisis. A common thread throughout all of the interviews was a commitment to their clients that the organization will be there tomorrow and for years to come. Given this ideological frame of constantly keeping in mind the future of the organization, the Helping House has identified changing funding dynamics as being a significant to the capacity and continuity of their mission. As the organization is well known in the immigrant community and trusted as a resource, there is a lot of pressure to fulfill the community's expectations and helping people as long as there is need. Every person who was interviewed at some point expressed the desire of continuing the mission of the non-profit because of the important work that it does; this was without any prompting but rather came up when simply discussing the work that goes on at the organization.

Building Capacity and Continuity Through Human and SocioOrganizational Resources

Because this organization has significant involvement in legal services for immigrants there is a unique constraint as to the extent to which resources can be mobilized. As was mentioned earlier, the only two legal remedies available for undocumented immigrants at this time are Deferred Action and visas for victims of crimes. Policy is a large restriction on how much the Helping Hand can assist the community. Even so, the non-profit has found ways to leverage human and socio-organizational resources to maximize the possibilities of legal remedies. An example of this can be found in a newly developed program to combat Notario fraud. The problem of notario fraud was identified at the Helping House when a number of lawyers reported hearing or seeing the implications of notario's from their clients. Some would mention that a notario was holding their passport and swindled money from them; while some were faced with more serious consequences of visiting a notario such as being ineligible for legal relief due to immigration paperwork being filed incorrectly in the past by notarios. Seeing this problem and mobilizing their socio-organizational resources, they met with other community leaders to find a remedy. Before the strategic decision was made by those in the organization to do this, the non-profit was powerless to do anything through traditional legal immigration remedies. Though these socio-organizational resources were important, the human resources involved were just as significant. Because of the expertise in law and interest in immigrant issues, the legal department developed a handbook for how to deal with notario cases. Their success in the courts is reflected in their framing of notario fraud as a consumer protection issues. Though the program is new, at the time of fieldwork three cases had already been won. Internally, there is a strong emphasis placed on being current on reforms to immigration policy and finding ways to make the law work for the client.

The one weakness in this strategy is though the legal department has found ways to utilize the flexibility of interpretation of the law at times; there is no advocacy arm of the organization. On social media and in daily conversations, the organization as a whole and the staff support comprehensive immigration reform and laws that will help with the social problems experience by immigrants, the organization does not engage in formal lobbying. There are two ways to view the lack of advocacy; as an organizational failure or as inappropriate for the non-profit. It is important to note that there have been times where the Helping House has been asked to be a part of developing public policy related to immigrant issues; specifically this happened in the early 1990s with the creation of the Violence Against Women Act. A few members of the Helping House were asked for their input when the bill was being drafted and were an important part of many of the protections for immigrant survivors of domestic violence and human trafficking. Since then, no significant lobbying is occurred even when the opportunity has presented itself. 
An example of this is the summer of 2013 when immigration reform passed in the senate, but the Helping House merely voiced its support for the bill on social media instead of being involved in the policy making process. Immigration would have a direct affect on the pool of clients the non-profit would be able to assist if immigration reform was passed, but as of right now the nonprofit has found no direct motive to be a part of that process. It could be argued that because their mission statement does not encompass advocacy, it is unnecessary for the organization to invest their human and cultural resources in this cause. If anything, this is another area that the Helping Hand could discuss being involved with in the future to maximize resource mobilization for their targeted population of Hispanic immigrant

\section{DISCUSSION AND CONCLUSIONS}

The purpose of this paper is to develop the understanding of resource mobilization within the non-profit. The social movements research on resource mobilization, strategic decisionmaking, and capacity and continuity presents a starting point for understanding how non-profits can be effective, but does not fully explain the functioning of the non-profit. Through the analysis of field observations and qualitative interviews, a model was built to better explain how the non-profit mobilizes resources and makes strategic decisions to build organizational capacity and continuity.

The findings from this case study are significant for Hispanic immigrants, resource mobilization strategies of nonprofits, and sociological theory. This analysis brings to light the importance of planning to be sustainable, community support, relationships with other non-profits, and inclusive internal discussion for the maximization of resource. This examination presents several strategies of successful non-profits. Much of the resource mobilization framework in this non-profit is developed, constantly being refined, and stable. At the same time, it highlights the struggles that even established organizations face, especially in the face of increased immigration to an area. For the non-profit, this case study provides an outside evaluation of how effective they are with their resources. It provides suggestions of ways that they can maximize their abilities to continue to serve their clients (mainly Hispanic immigrants) as well as possible.

In terms of sociological theory, this investigation presents compelling evidence for the importance of understanding the role of non-profits in social change. Though policy is a significant limiting factor on the amount of social change and resource redistribution the organization can accomplish, the non-profit has a sustained direct effect on communities. Looking at the organizations in terms of resource mobilization can help identify ways that this mobilization can be improved, while also deepening the scholarship on what makes an effective non-profit. This would provide tangible benefits for individual non-profits in trying to better fulfill their mission, but also advance literature on non-profits past a very business-like focus on how management decisions affect the organization's success. Through examining the non-profit in terms of resource relationships instead of solely on internal decisions, a more nuanced understanding can be grasped on how non-profits can have maximum impact. 


\section{REFERENCES}

Arizona vs. United States. 2012. "Opinion No. 11-182. Argued April 25, 2012—Decided June 25, 2012". (http://www.supremecourt.gov/opinions/11 pdf/11-182.pdf)

Deane, C. T. 2007. Chief's Memorandum to BOCS on Department Immigration Policy. Letter from Charlie T. Deane, Chief of Police, to the Board of County Supervisor.

De Leon, Erwin, Matthew Maronick, Carol J. De Vita, Elizabeth T. Boris. 2009. “Community-Based Organizations and Immigrant Integration in the Washington D.C. Metropolitan Area. The Urban Institute: Center on Nonprofits and Philanthropy.

Downey, Dennis J., and Deana A. Rohlinger. 2008. “Linking Strategic Choice with MacroOrganizational Dynamics: Strategy and Social Movement Articulation" Research in Social Movements, Conflicts and Change. 28:3-38.

Edwards, Bob, and Patrick F. Gillham. 2013. “Resource Mobilization Theory”The Wiley-Blackwell Encyclopedia of Social and Political Movements. Wiley-Blackwell: Hoboken, New Jersey.

Edwards, Bob, and John D. McCarthy. 2007. Resources and Social Movement Mobilization, in The Blackwell Companion to Social Movements, (eds D. A. Snow, S. A. Soule and H. Kriesi), Blackwell Publishing Ltd: Oxford, UK. 116-152

Executive Office of the Mayor. 2011. “Mayor Vincent C. Gray Signs Order Protecting Residents from Unnecessary Inquiries into Immigration Status"The District of Columbia.

Finnie, R. and R Meng. 2005. “Literacy and labour market outcomes: self-assessment versus test score measures" Applied Economics. 37(17):1935-1951.

Flippen, Chenoa A. "Laboring Underground: The Employment Patterns of Hispanic Immigrant Men in Durham, North Carolina" Social Problems. 59, no. 1 (2012):21-42.

George Mason University Center for Regional Analysis. "Update from the 2010 Census: Population Change in the Washington DC Metropolitan Area" CRA Census Series. 2011.

Guterbock, Thomas M., Milton Vickerman, Christopher S. Koper, Bruce Taylor, Karen E. Walker, and Timothy Carter. 2010. “Evaluation Study of Prince William County's Illegal Immigration

This work is licensed under a Creative Commons Attribution-

NonCommercial-

NoDerivs 3.0

Unported License. Enforcement Policy FINAL REPORT 2010". Prepared for the Prince William County Police Department.

Hall, Matthew, Emily Greenman, and George Farkas. 2010.“Legal Status and Wage Disparaties for Mexican Immigrants". Social Forces. 89(2):491-513. 
Hazen, Andrea L., and Fernando I. Soriano. 2007. “Experiences with intimate partner violence among Latina women"Violence Against Women. 13, no. 6 (2007):562-582.

--- Hispanic Interest Coalition of Alabama, et al. vs. Robert Bentley, in his official capacity as Governor of the State of Alabama, et al..2011. “Memorandum Opinion" United States District Court Northern District of Alabama.

Hoefer, Michael, Nancy Rytina, and Bryan Baker. 2012. “Estimates of the Unauthorized Immigrant Population Residing in the United States: January 2011". Population Estimates. Department of Homeland Security.

Huxham, Chris and Siv Vangen. 1996."Working together in key themes in the management of relationships between public and non-profit organizations"The International Journal of Public Sector Management. 9(7):5-17

Ingram, Maia, Deborah Jean McClelland, Jessica Martin, Montserrat Caballero, Maria Theresa Mayorga, and Katie Gillespie. 2010. “Experiences of Immigrant Women Who Self-Petition Under the Violence Against Women Act"Violence Against Women. 16(8):858-880

Kullgren, Jeffrey T. 2003. “Restrictions on Undocumented Immigrants' Access to Health Services: The Public Health Implications of Welfare Reform" American Journal of Public Health 93(10):1620-1633.

Logan, T.K., Robert Walker, and Gretchen Hunt. 2009. “Understanding Human Trafficking in the United States". Trauma Violence \& Abuse. 10(1):3-30.

Parrado, Emilio A., and William Kandel. 2011. "Industrial change, Hispanic immigration, and the internal migration of low-skilled native male workers in the United States, 1995-2000" Social Science Research. 40(2):626-640.

Passel, Jeffrey S., D’Vera Cohn, and Ana Gonzalez-Barrera. 2013. “Population Decline of Unauthorized Immigrants Stall, May Have Reversed: New Estimate 11.7 million in 2012" Pew Hispanic Center.

Pew Hispanic Center tabulations of the 2010 ACS. 2011. "Characteristics of the Population in the District of Columbia, by Race, Ethnicity and Nativity: 2010". Pew Hispanic Center. Pew Research Hispanic Center Hispanic Trends Project. 2012."Demographic Profile of Hispanics in District of Columbia, 2011". Pew Hispanic Center

Prince William County Government. 2013. "Illegal Immigration Enforcement-An Introduction". Prince William County Police Department. 
Raymond, Janice G., and Donna M. Hughes. 2003. "International and Domestic Trends in Sex Trafficking of Women in the United States, 1999-2000" Inter-university Consortium for Political and Social Research.

Rizo, Cynthia F. and Rebecca J. Macy. 2011. "Help seeking and barriers of Hispanic partner violence survivors: A systematic review of the literature". Aggression and Violent Behavior. 16(3):250-264.

US Census Bureau. 2011. "2010 Census Shows Nation's Hispanic Population Grew Four Times Faster Than Total U.S. Population".

Walker, Edward T. \& John D. McCarthy. 2010. "Legitimacy, Strategy, and Resources in the Survival of Community-Based Organizations". Social Problems. 57(3):215-240.

Zald, Mayer N., and John D. McCarthy. 1987. Social Movement Industries: Competition and Conflict Among SMOs, in Social Movements in an Organizational Society: Collected Essays. 161-180.

Zald, Mayer N., and Bert Useem. 1987. Movement and Countermovement Interaction: Mobilization, Tactics, and State Involvement, in Social Movements in an Organizational Society: Collected Essays. 247-272. 